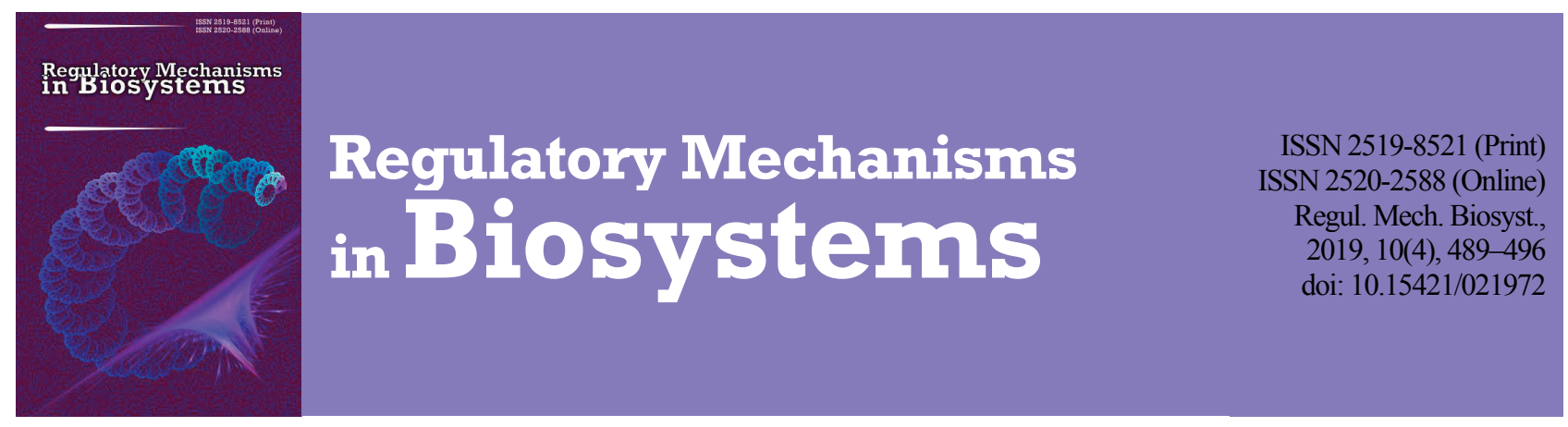

\title{
Experimental study of tropism in cultivated canine coronavirus in the small intestine of puppies
}

\author{
L. Goralskii*, N. Radzikhovsky*, O. Dyshkant*, O. Dunaievska**, I. Sokulskiy* \\ *Zhytomyr National Agroecological University, Zhytomyr, Ukraine \\ **Municipal Institution of Higher Education Zhytomyr College of Pharmacy Zhytomyr Oblast Council, Zhytomyr, Ukraine
}

Article info

Received 15.10.2019

Received in revised form 17.11.2019

Accepted 18.11.2019

Zhytomyr National Agroecological University, Stary Boulevard, 7, Zhytomyr 10002, Ukraine.

Tel.: +38-041-233-39-50.

E-mail:znaudilovod@i.ua

Municipal Institution of Higher Education Zhytomyr College

of Pharmacy Zhytomyr

Oblast Council, Zhytomyr 10002, Ukraine

Tel.: +38-041-224-25-45

E-mail:pharm@ukrpost.ua

Goralskii, L., Radzikhovsky, N., Dyshkant, O., Dunaievska, O., \& Sokulskiy, I. (2019). Experimental study of tropism in cultivated canine coronavirus in the small intestine of puppies. Regulatory Mechanisms in Biosystems, 10(4), 489-496. doi:10.15421/021972

The varying extents of natural disease induced by coronavirus in dogs are not completely clear because the pathogenesis of coronavirus enteritis is not studied sufficiently. In this study, based on the results of clinical, virological, morphological and histochemical studies, we determined the pathogenic role of coronavirus in infected dogs using experimental infection, per os, of isolated canine coronavirus (Nick) with titer of infectious activity equaling $4.8 \pm 0.04 \mathrm{lg} \mathrm{TCID} / \mathrm{cm}$, cultivated on heterologous cell cultures. This allowed us to determine, supplement, and generalize the data on pathogenesis of the disease and determine the histological changes in the small intestine, where the initial replication of the pathogen takes place. It was found that lesions and the pattern of the pathomorphological changes (destruction, necrosis and edema of the stroma of the villi, lysis of the cytoplasm, deformation of the enterocyte nuclei) in the small intestine of experimentally infected dogs depend on the development of the pathological process related not only to the changes in histoarchitectonics of the wall of the intestine, but also to tension of the histochemical statics, and obviously the dynamic of the cells (accumulation of the main and acidic proteins in enterocytes' cytoplasm, hypersecretion of the mucus by goblet cells, decrease of Schiff iodine acid-positive substances in the enterocytes' cytoplasm, formation of basophilous inclusion bodies), which leads to disorders in metabolic processes in the organism of infected dogs as a response to the virus infection. The examined dogs were found to have morphological changes in the small intestine similar to those in spontaneously infected animals. During the action of coronavirus, the contacts between the enterocytes become damaged, which leads to inhibition of the protective functions of the intestine. At the same time, the pathological process in the experimentally infected animals developed rapidly and had an acute course. Thus, coronavirus enteritis as a separate disease is practically unobserved in field conditions, which makes microscopic survey of the pathogenic impact of the latter on the organism of dogs impossible. Therefore, experimental mono-infection allows a detailed study to be conducted of pathomorphological changes of the initial place of the reproduction of the virus - the small intestine affected by coronavirus enteritis.

Keywords: pathological anatomic dissection; histological changes; enterocytes; villi; inclusion bodies.

\section{Introduction}

Currently, virus infections are at the stage of deep study. Veterinary and medical virologists regularly discover new pathogens as modern technologies develop and new knowledge in this sphere is obtained. The historic route of study of the coronavirus enteritis of dogs began in 1971, when the virus was isolated from feces of a military dog in Germany. Since then, up to the present, the disease has been studied by many scientists around the world (Decaro et al., 2010; Godsall et al., 2010; Licitra et al., 2014) and several strains of the virus have been discovered, the pathogenicity of which varies from intestinal (enteritic) to lung (respiratory) form. Recently, in the world literature, reports on pantropism of the canine coronavirus have emerged (Woo et al., 2010; Mitchell et al., 2013).

Over the past few years, an increase in the cases of infection among dogs with signs of diarrhea has been reported not only in Ukraine, but in Europe. A complex of laboratory studies has revealed the presence of not only parvo-, but also corona- and rotavirus enteritis. These enteritides are extremely dangerous for puppies and miniature-sized dogs as they cause rapid dehydration, and as a result lead to lethal outcome (Yashchuk et al., 2014; Radzikhovsky, 2016). One of the commonest reasons of infectious diarrhea in dogs are virus enteritides - parvovirus and coronavirus, which usually manifest as initial pathogens of enteri- tides of virus etiology (Goddard \& Leisewitz, 2010; Godsall et al., 2010; Caddy, 2018). Coronavirus infections are a group of acute infectious diseases caused by coronaviruses pathogenic for humans and animals. Among mammals, most often the virus infects swine, cattle, dogs, cats, rodents (Decaro et al., 2010; Netherton \& Wileman, 2011). These diseases are mostly of newborn and young agricultural and domestic animals, caused by coronaviruses, which manifest affinity mostly to the epithelium of the digestive tract and respiratory paths. In infected puppies, the main sign is diarrhea syndrome (Mark et al., 2011; Ntafis et al., 2011; Zicola et al., 2012). Coronavirus is an acid-resistant pathogen, therefore undergoes special changes in the stomach of animals. At the same time, viremia and generalized infections are not observed. However, superficial epithelium of the mucous membrane of the small intestine is the main target of the coronavirus; by contrast, the large intestine is resistant to the infection (Levy et al., 2000; Mihindukulasuriya et al., 2008; He et al., 2014). It was determined that with enteroviruses the main pathogenic factor is affinity to cells with fast proliferation, particularly epithelial cells of the small intestine, desquamation of which results in destruction of the protective barrier, thus leading to bacterial translocation. After entering Peyer's patches of the intestine through epithelium, the virus is transported to the lymphoid tissue. Presumably, after having had entered the lymphoid tissue of the intestine, it accumulates there, further leading to a latent course of this disease. All this leads to 
development of a significant endogenous intoxication (Denison et al., 2011; Szczepanski et al., 2018). As for accumulation of coronavirus by cultivating it on cultured cells, currently most coronavirus isolated from dogs is cultivated in vitro on the cell cultures obtained from the organs of dogs and cats (Poder, 2011; Vlasova et al., 2011).

Extents of natural coronavirus-induced disease in dogs are rather unclear, for pathogenesis of coronavirus enteritis of dogs is characterized incompletely. Earlier, it has been reported that the infection is related to moderate or severe gastroenteritis; currently CVI is being found to be mostly a mild or subclinical disease of animals and has low parameters of mortality (Mitchell et al., 2013; Caddy, 2018). For many years the coronavirus as a pathogen received insufficient attention by both veterinary doctors and those in human medicine. This had a negative influence as shown by an outbreak of atypical pneumonia in people in 2002. Since then coronavirus infections have been given proper attention and are being studied at a more perfect level (Buonavoglia et al., 2006; Evermann et al., 2015). It should be noted that in natural conditions the coronavirus infection is usually recorded in association with other virus, bacterial or parasitic agents, which also cause similar clinical features. Therefore the objective of this study was to determine the peculiarities of morphofunctional changes in the small intestine during experimental recreation of coronarirus enteritis for revealing and substantiating pathogenesis.

\section{Materials and methods}

In the course of our research, we followed the main rules of the relevant laboratory practice GLP (1981), requirements of the "General ethical principles for experiments on animals" approved by the I National Congress of Bioethics (Kyiv, 2001). The entire experimental part of the study was performed according to the requirements of the international principles of the "European Convention on Protection of Vertebrate Animals used in Experiments and other Scientific Purposes" (Strasbourg, 1985), "Rules of conducting work with use of experimental animals", approved by order No 281 of the Ministry of Healthcare of Ukraine from 01.11.2000 "On measures for further improvement of the organizational forms of work with experimental animals" and therefore the law of Ukraine "On protection of animals against cruel treatment" (No 3447-IV from 21.02.2006, Kyiv). The protocol of the study was approved by the Commission of Bioethical Expert Examination and was allowed by the Zhytomyr National Agroecological University (No 1 from 27.02.2018).

For the experiment we used 5 dogs aged 45 days, Labrador mongrel metis. The animals were in satisfactory condition without any signs of infection or pathology. To prevent the impact of parasitic agents, on the 21st and 34th days after their birth, the dogs underwent dehelminthization using the anthelmintic preparation Pirantel. The puppies were put in separate boxes in an infection isolator, and tested for absence of infection in immune strips (Immune-Chemical Analysis) using diagnostic test systems VetExpert (CAV Ag, CDV Ag, CPV/CCV $\mathrm{Ag}$ and Rota $\mathrm{Ag})$.

After acclimatization and adaptation, the puppies weighing $2.95 \pm$ $0.11 \mathrm{~kg}$ were divided into two groups, in the first the animals were infected by coronavirus, the second was the control for determining spontaneous occurrence of the disease in case of infection before the experiment. For infection we used field coronavirus isolated and confirmed by PLR, obtained from a dead dog. The infected biological material was cultivated on heterological cell cultures, implantation lines of cultures of cells SPEV (kidneys of a pig embryo), BHK-21 (kidneys of Syrian hamster), RK-13 (kidneys of rabbit). In the experiment we used cultivated virus isolates frozen at minus $24^{\circ} \mathrm{C}$. Before use, they were defrosted at room temperature and from time to time the mat with cultural liquid was shaken to promote rupture of the cells and exit of the virus. The examined animals were infected per os once a day in the dose of $5 \mathrm{~mL} / \mathrm{kg}$ of suspension of the strain with titer of infectious activity of $4.80 \pm 0.04 \mathrm{lg} \mathrm{TCID}{ }_{50} / \mathrm{cm}$. The clinical condition of each dog was checked every day over 10 days. On the 8-9th days the following clinical manifestations were observed: vomiting, diarrhea, depression, loss of appetite, beginning of dehydration. On ethical grounds, euthanasia was performed.

In the experiment, we used canine coronavirus Nick, for the first time isolated in the territory of Ukraine, which has been included in the Depository of Scientific Control Institute of Biotechnology and Strains of Microorganisms during initial depositing (registration number given to the strain of microorganism by the Depository: 735, from 10.12.2018).

Autopsy of the animals was made in the Prosectorium of the Anatomy and Histology Department of the Faculty of Veterinary Medicine of Zhytomyr National Agroecological University. Material of the study was the small intestine extracted from puppies $(n=5)$ during pathological dissection, after humane euthanasia using thiopental (sodium thiopental), according to the European Convention for the Protection of Vertebrate Animals used for Experimental and Other Scientific Purposes (Decaro et al., 2008; Decaro et al., 2012; Mitchell et al., 2013).

Presence of coronavirus, without any associates, in these cases was confirmed by immunoenzymic analysis (IEA) and immunochromatographic analysis (ICA) during analysis of samples of feces.

For histological studies, the extracted material was immediately fixed in $10 \%$ aqueous solution of neutral formalin, followed by embedding into paraffin. For histological detection of nucleic acids of proteins of glycosaminoglycans and SIA-positive substances, Carnoy's solution was used as a fixative agent. After deparaffinization, the prepared histological sections were stained with Carazzi's hematoxylin and eosin. For detecting content and intracellular localization of DNA and RDA, the sections were stained with gallocyanine-chromium alums according to Einarson's method. The main and acidic proteins were detected according to the Michel-Calvo technique, glycosaminoglycans - Steedman alcian blue. Schick positive substances were detected using Schiffiodine acid according to Mc Manus (Goralsky et al., 2015).

General histological structure and microstructural changes in the histological preparations were studied under a light microscope MC 100LED (Micros Austria) in 70 to 1,000 times magnification. Microphotography of the histological preparations was carried out using a CAM V200 videocamera installed into a Micros MC 50 microscope.

\section{Results}

As a result of the pathological dissection, in the lumen of the duodenum, jejunum and ileum of the studied dogs, cellular detritus was detected. In the puppies infected by coronavirus, in the lumen of the small intestine, quite large layers of villi epithelium dominated (Fig. 1). Quite large areas of villi were observed to show notable microscopic changes (Fig. 2).

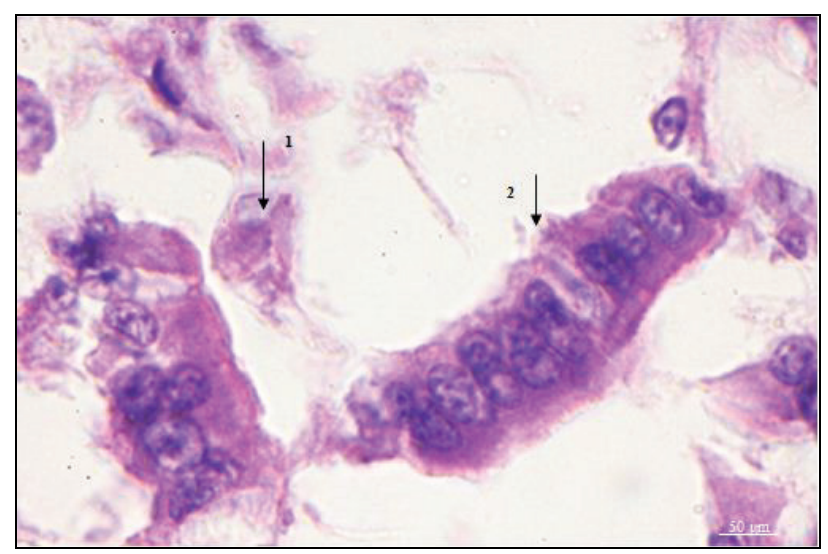

Fig. 1. Fragment of microscopic structure of the jejunum of an experimentally infected puppy: 1 - cellular detritus in the lumen of the intestine; 2 - fragment of epithelium of a villus; hematoxylin and eosin

During histochemical surveys, in the cytoplasm of the enterocytes present in the content of the fragments of villi in the lumen of the small intestine, which were destroyed less, the main proteins dominated. However, as far as the destruction of enterocytes went, grains of acidic proteins in their cytoplasm accumulated (Fig. 3). Taking into account that in cytoplasm of enterocytes on the surface of villi of the small intes- 
tine, only main proteins were found (Fig. 4), and that with development of the pathological process, according to the results of our studies, acidic ones emerged, we consider that destruction of enterocytes of the villi in the small intestine of the puppies experimentally infected with a coronavirus, which we isolated and cultivated in heterologous cell culture, took place simultaneously with accumulation of the main and acidic proteins in their cytoplasm.

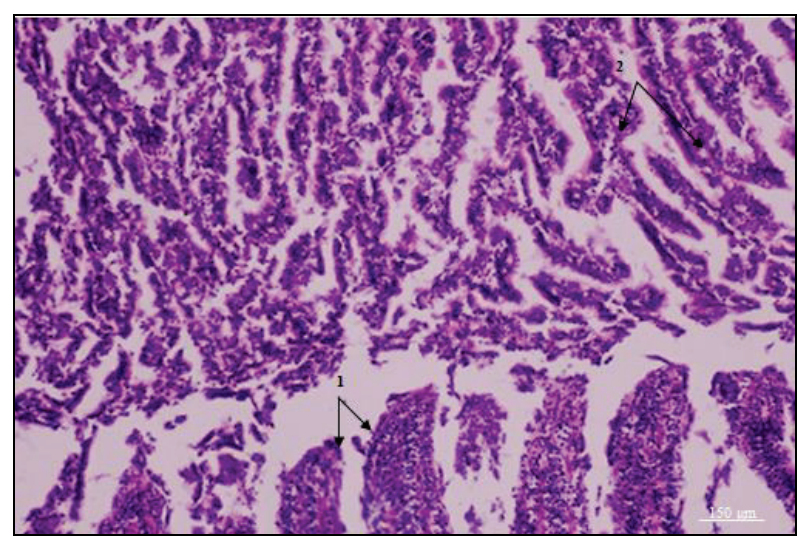

Fig. 2. Fragment of microscopic structure of the jejunum of an experimentally infected puppy: 1 - villi of the mucous membrabe;

2 - fragments of villi in the lumen; hematoxylin and eosin

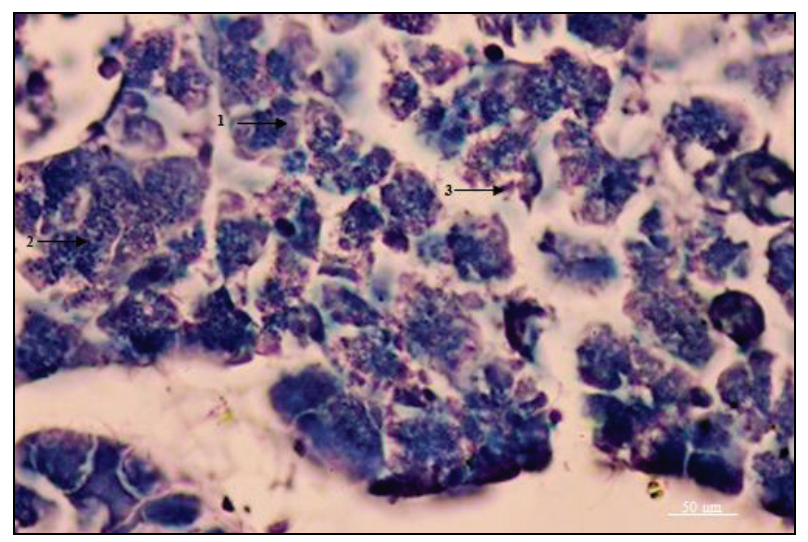

Fig. 3. Enterocytes in different stages of destruction in the lumen of the jejunum: 1 - main proteins in cytoplasm of a less ruined enterocyte; 2 - grains of acidic proteins in cytoplasm of an enterocyte; 3 -domination of acidic proteins of a more ruined enterocyte; Michel-Calvo staining technique

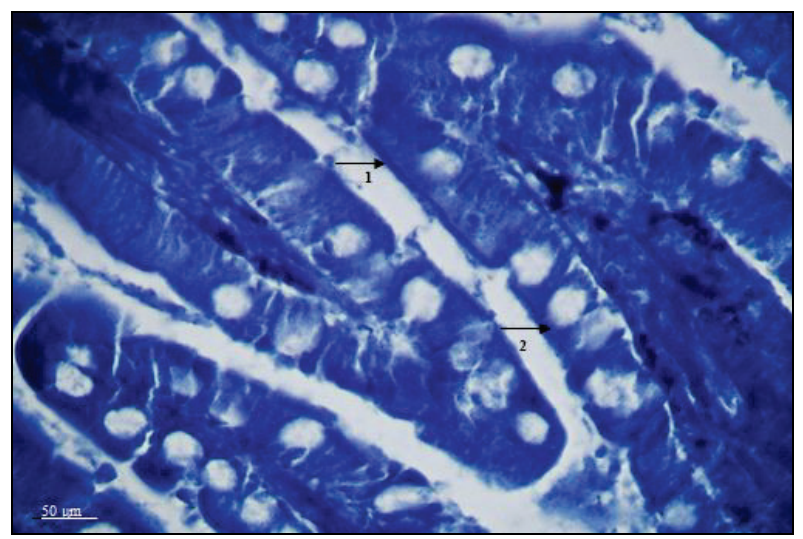

Fig. 4. Fragment of microscopic structure of the duodenum of an experimentally infected puppy: 1 - enterocytes of villi; 2 - goblet cell; Michel-Calvo technique

Histological studies revealed that microscopic changes in the villi in different areas of the small intestine varied. In most cases, villi of the duodenum, jejunum and ileum were partly or completely destroyed. Therefore only remains of villi were found in their mucous membrane, and often villi were completely absent. In many cases, proximate remains of villi which were not covered with epithelium were located, and adhered together at their apices and lateral surfaces (Fig. 5). Often mutual adhesion of two remains of closely located villi was observed. At the same time, in some places, sticking together of three and more of such villi was seen. In separately-standing areas of histopreparations of the duodenum, jejunum and ileum, the pattern of microscopic changes was somewhat different - necrosis of apical parts of villi was observed (Fig. 6). In small amount, villi with preserved epithelium were observed (Fig. 7). However, on their tips, epithelium was destroyed (Fig. 8), as a result part of the villi, especially their apical surface was not covered with epithelium (Fig. 9).

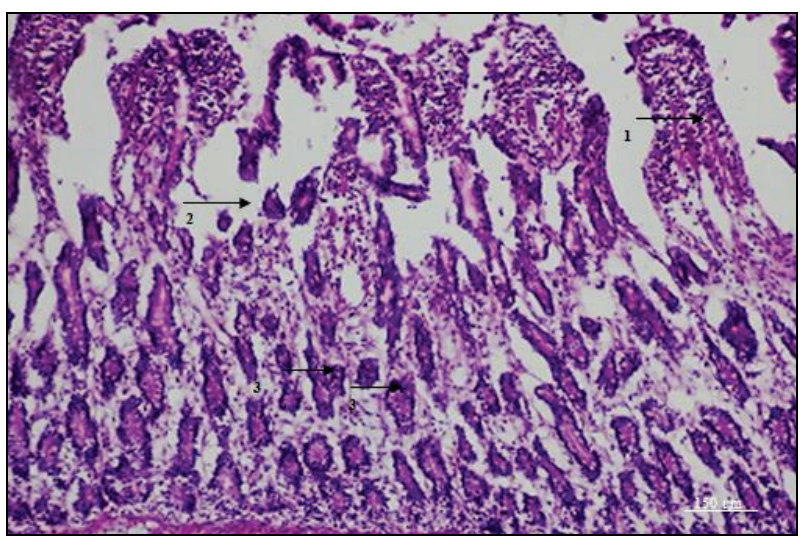

Fig. 5. Fragment of microscopic structure of the ileum of an experimentally infected puppy: 1 -adhering together of remains of villi of the mucous membrane; 2 - absence of villi; 3 -crypts; hematoxylin and eosin

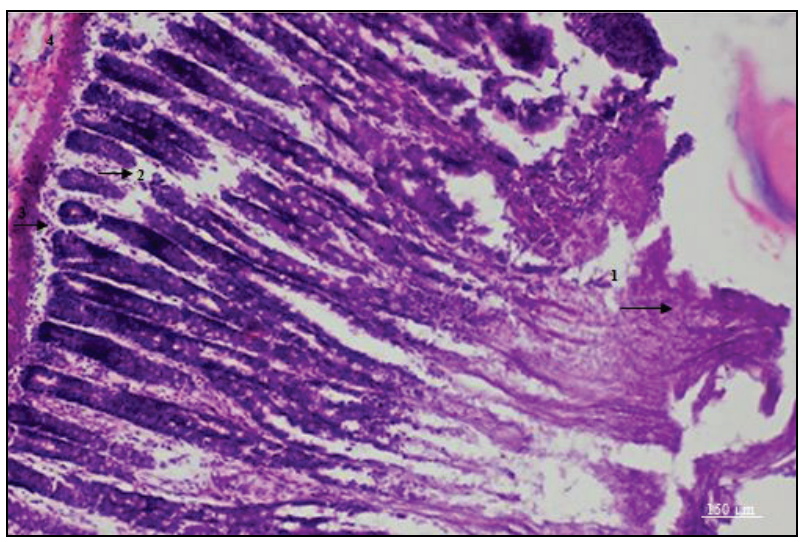

Fig. 6. Fragment of microscopic structure of the duodenum of an experimentally infected puppy: 1 - necrosis of the apices of villi; 2 - edema in the area of crypts; 3 - grainy dystrophy of myocytes of the muscularis mucosae of the mucous membrane; 4 - edema of the submucosa; hematoxylin and eosin

In cytoplasm of some separate enterocytes, during staining of histopreparations with gallocyanine-chromium alums, intensively stained small-sized spots of rounded shape were seen, which was clearly distinguished against the general background of stained cytoplasma (Fig. 7).

During staining of histopreparations with gallocyanine-chromium alums, the staining agent bound in a specific way to nucleic acids in stoichiometric ratios, and we can state that such dense breeding-ground accumulations of nucleic acid, where concentration of the latter significantly increased its regular content in the cytoplasm, can be places of concentration of nucleic acid of coronavirus. During staining of histological samples of the small intestine with hematoxylin and eosin, we found basophilous inclusion bodies in apical and middle parts of cytoplasm of separate enterocytes of villi (Fig. 10). They had probably been formed as a result of infection of enterocytes of the villi of the small intestine by the pathogen of the disease and are a virus replication complex. Furthermore, during our histochemical surveys, we determined 
that the content of DNA and RNA significantly decreased in the cytoplasm and nucleus of the ruined enterocytes which formed villi of the small intestine (Fig. 8).

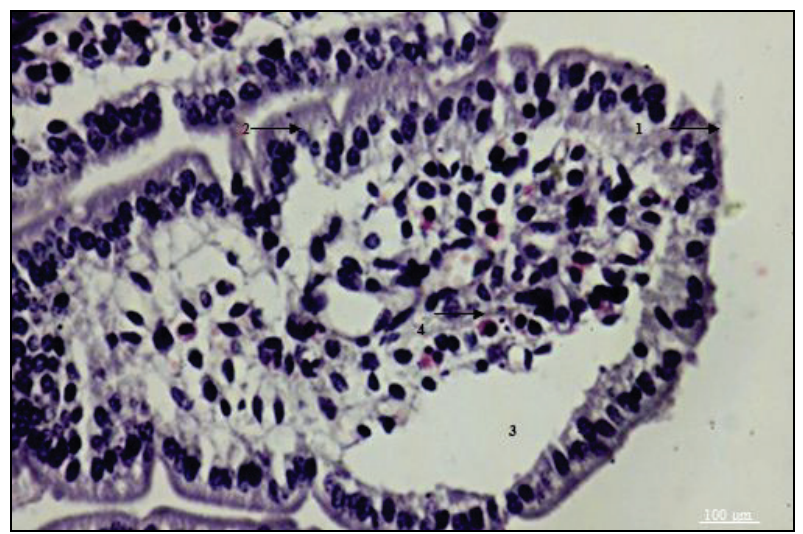

Fig. 7. Fragment of microscopic structure of the jejunum of an experimentally infected puppy: 1 - villi with preserved epithelium; 2 - center of dense accumulation of nucleic acids in the cytoplasm of an enterocyte; 3 - subepithelial edema with deformation of a vill; 4 - mast cell; gallocyanine-chromium alums

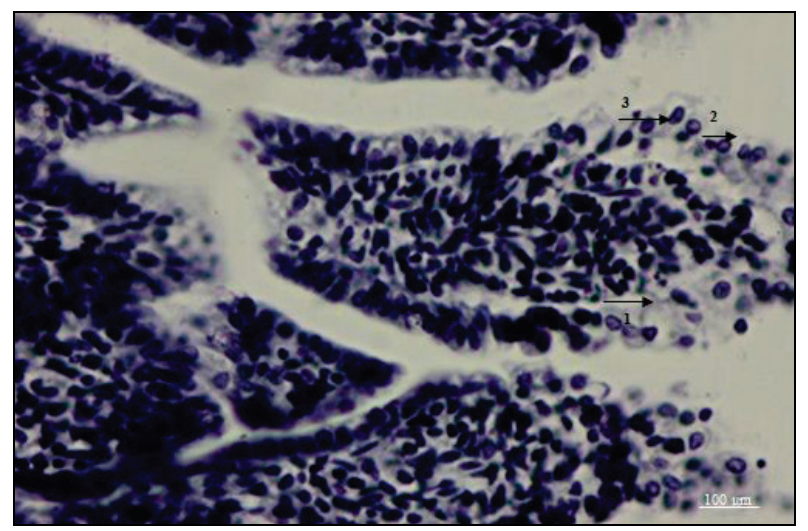

Fig. 8. Fragment of microscopic structure of the jejunum of an experimentally infected puppy: 1 - destruction of epithelium on the apex of a villus; 2 - decrease in the content of DNA in the nucleus of an enterocyte undergoing destruction; 3 - reduction of RNA content in cytoplasm of an enterocyte undergoing destruction; gallocyanine-chromium alums

In villi with no epithelium on the apical surface (Fig. 9), we usually partly observed its destruction on their lateral surfaces as well. In most cases, epitheliocytes of villi were in the condition of granular dystrophy (Fig. 10). At the same time, in separate dystrophically changed erythrocytes, their striped fringing was preserved, in others it was absent, which indicates significant facilitation of their cellular membranes. In separate enterocytes of villi, ruination was seen in their apical part of cytoplasm. Apart from the changes mentioned above, in some cases, we recorded dys-complectation of adjacent enterocytes with signs of granular dystrophy (Fig. 10), which indicates significant damage to cellular contacts.

On the remains of villi of the small intestine, hypersecretion and exhaustion of goblet cells were seen (Fig. 11). Such hypersecretion of mucus by goblet cells, in our opinion, is one of the protective mechanisms in the small intestine, at least with different virus enteritides, and during prolonged intestinal virus infection, with time this system of non-specific immunity is exhausted.

During performance of SIA-reaction, the content of carbonic compounds in the cytoplasm of erythrocytes significantly decreased (Fig. 12), which we think indicates energetic exhaustion of these cells. Notable penetration of carbonic compounds through the basal membrane of epithelium of villi took place (Fig. 12). Therefore, taking into account the absence of such changes during staining of histosections in different areas of the small intestine using alcian blue in $\mathrm{pH}$ of 1.0 and 2.5 (Fig. 11), we came to the conclusion that during the experimentally recreated coronavirus infection, mucoid edema of the basal membrane of epithelium of the small intestine with neutral glycosaminoglycans occurred. Furthermore, experimental coronavirus enteritis led to accumulation of SIA-positive compounds in the lumen of the intestine between villi. Among such SIA-positive substances, intensely stained SIA-positive granules in the lumen of the intestine between villi were found (Fig. 12). At the same time, stroma of villi of the small intestine had non-uniform edema - in one and the same vill, in most cases, areas of insignificant edema of stroma were found along with its gradual edema and extremely notable edema (Fig. 7, 9, 13). Such edema led to notable deformation of villi.

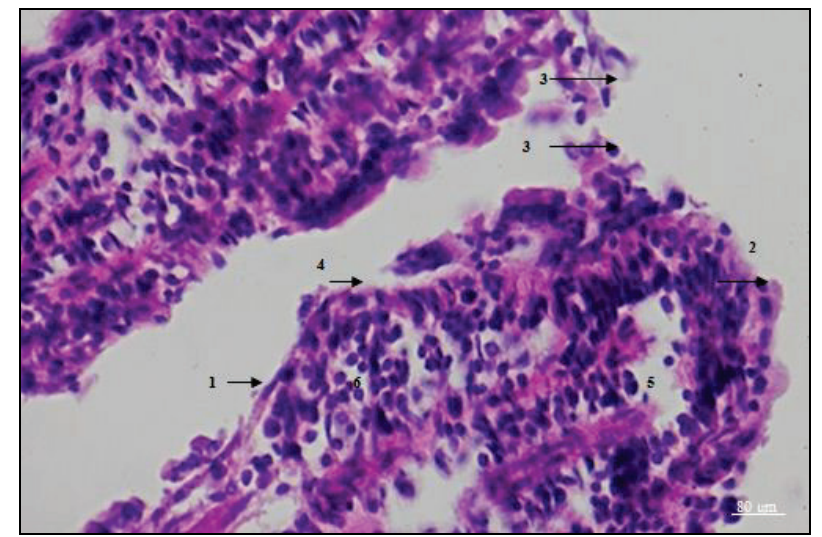

Fig. 9. Villi of the ileum of an experimentally infected puppy: 1 -absence of epitheliocytes on the lateral surface of a villus, 2 - epithelium on the surface of a villus; 3 - ruination of epithelium of villi; 4 - area of deformation of a villus; 5 - edema of the stroma;

6 -lymphocytes in the stroma of a villus; hematoxylin and eosin

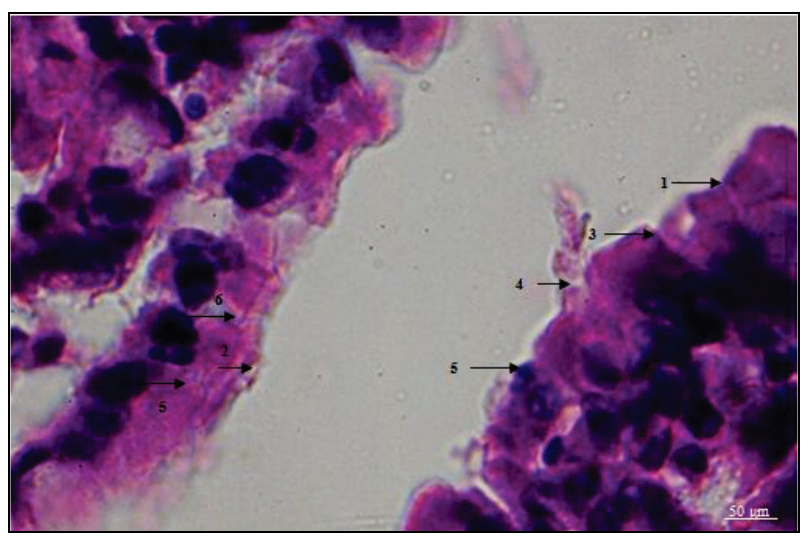

Fig. 10. Villi of the ileum of an experimentally infected puppy:

1 - granular dystrophy of enterocytes; 2 - striped fringe of dystrophically changed enterocytes; 3 - absence of striped fringe;

4 - ruination of apical part of cytoplasm; 5 - basophilous inclusion bodies; 6 - discomplectation of adjacent enterocytes; hematoxylin and eosin

In some cases the epithelium was absent in the area of edema of the stroma of villi, in other cases enterocytes in such areas had signs of granularity (Fig. 9), more rarely - hydropic (Fig. 13) dystrophy. In such cases hydropic dystrophy led to progressive lysis of cytoplasm and deformation of nuclei of enterocytes, and in some cases - to partial lysis of nucleus. In the area of edema of stroma, necrosis, ruination and lysis of its cells were observed (Fig. 13). Near those areas, the stroma of all villi of the small intestine without exception was non-uniformly infiltrated by lymphocytes (Fig. 9).

In puppies which were experimentally infected with the coronavirus isolate which we isolated and cultivated in heterologous culture of cells, notable microscopic changes in the small intestine were also found in the area of crypts. Such changes had no clear pattern in relation to dif- 
ferent areas of the small intestine. However, the extent of such changes clearly correlated with the extent of changes in villi-the more villi were ruined, the severer were the microscopic changes in the crypts. In areas of the small intestine, where villi were relatively well preserved, we observed granular dystrophy of enterocytes of crypts, accompanied by moderate edema of mucous membrane in the area of crypts (Fig. 5). In the areas where we observed more notable ruination of villi, in the crypts we found granular dystrophy of enterocytes, clear subepithelial edema and ruination of a certain amount of the epithelial cells (Fig. 14). In the areas of the small intestine, where the ruination of villi was greatest, granular dystrophy was found only in some of the crypt enterocytes. Most of the epithelial cells were at different stages of hydropic dystrophy. At the same time, the process started from partial lysis of cytoplasm of cells in the condition of granular dystrophy. Usually lysis of cytoplasm began in the basal part of enterocytes of the crypts (Fig. 15).

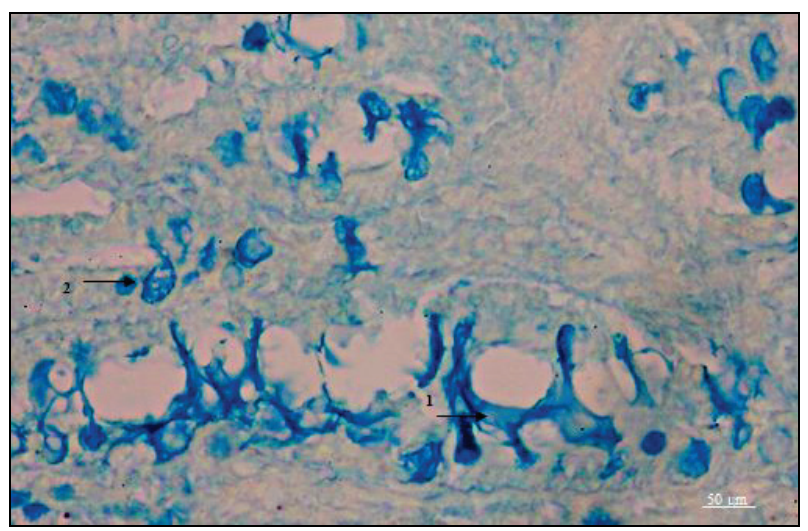

Fig. 11. Fragment of microscopic structure of the duodenum of an experimentally infected puppy: 1 -hypersecretion of a goblet cell;

2 - non-uniform staining of a goblet cell; alcian blue (pH 2.5)

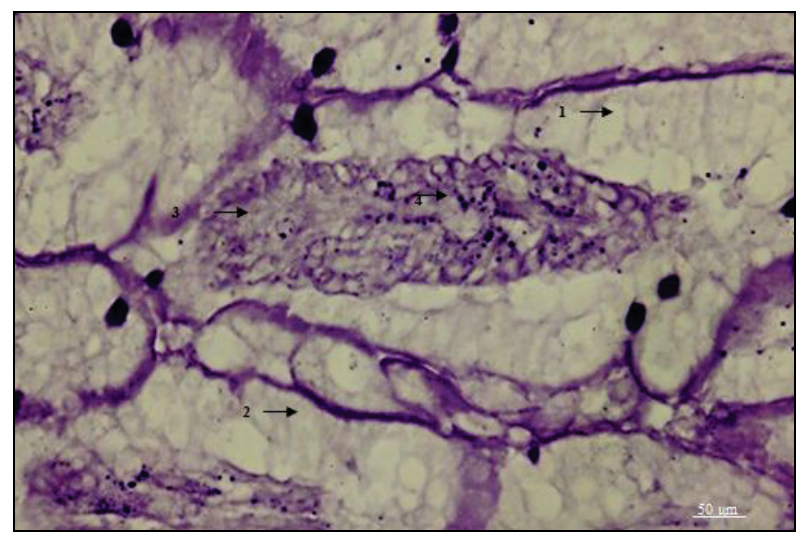

Fig. 12. Fragment of microscopic structure of vill of the ileum of an experimentally infected puppy: 1 -decrease in the content of

SIA-positive substances in cytoplasm of enterocytes; 2 - penetration through basal membrane of epithelium by SIA-positive substances; 3 -accumulation of SIA-positive substances in the lumen of the intestine between villi; 4 - intensively stained SIA-positive granules in the lumen of the intestine between villi

The study revealed that during even almost complete lysis of the cytoplasm, a thin strip of its apical part did not in most cases undergo lysis, and was in the condition of granular dystrophy (Fig. 16). In nuclei of a large amount of enterocytes of the crypts in the condition of hydropic dystrophy, we observed partial or almost complete lysis of chromatin, both functionally inactive heterochromatin and functionally active euchromatin. In the latter case, nuclear membrane was found in the cells, often partly ruined, with a small amount of pale hematoylin-stained chromatin inside (Fig. 16). Some of enterocytes of the crypts, which were in the condition of hydropic dystrophy, were ruined.

Smooth muscular cells of muscularis mucosae of the mucous membrane in all areas of the small intestine were in the condition of granular dystrophy (Fig. 5). In the submucosa of all sections of the small intestine, the microscopic changes were similar. Enlargement and overfilling with blood were seen in the blood vessels, and moderate edema of this layer (Fig. 5), and also swelling, disruption of the fibers and fragmentation of the bundles of collagen fibers were noted. In the duodenum, apart from that, we observed enlargement and hypertrophy of the duodenal glands. As a result of these changes, in some places these glands notably protruded into the mucous membrane (Fig. 17).

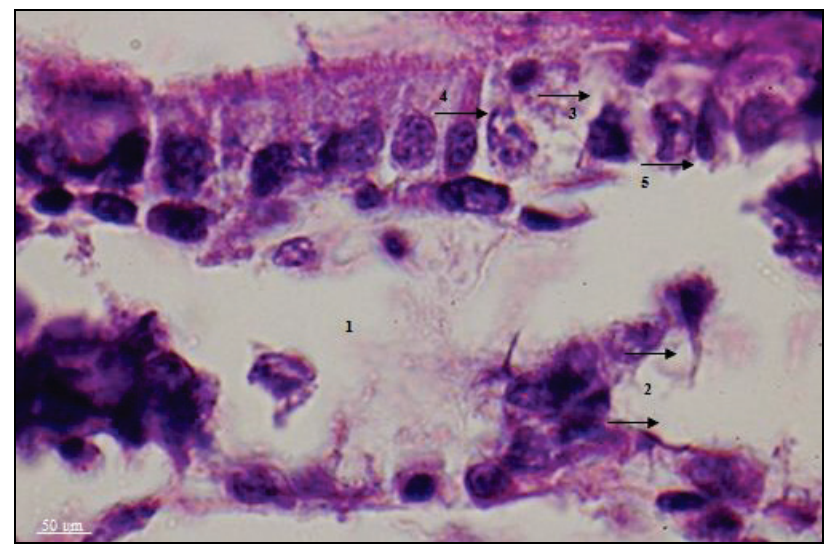

Fig. 13. Fragment of microscopic structure of the duodenum of an experimentally infected puppy: 1 - edema of the stroma;

2 - necrosis, ruination and lysis of cells of stroma; 3 - lysis of cytoplasm of enterocyte; 4 - partial lysis of nucleus of enterocyte; 5 - deformation of nucleus of enterocyte; hematoxylin and eosin

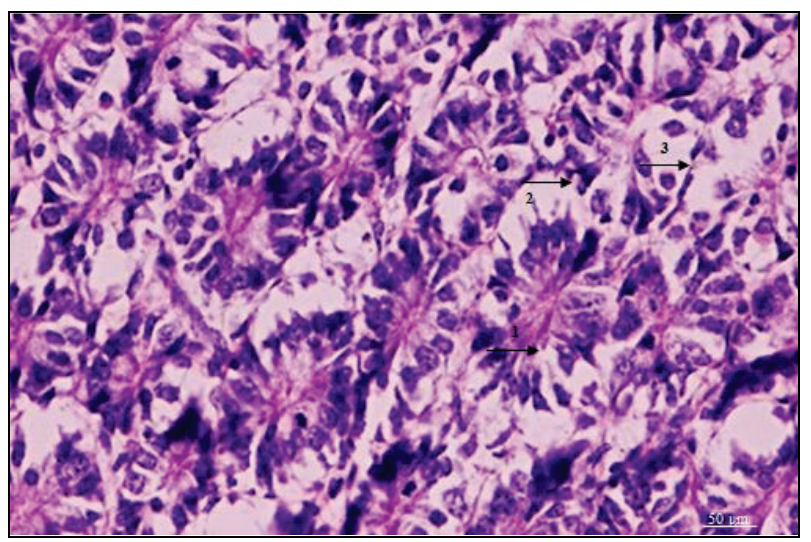

Fig. 14. Fragment of microscopic structure of crypts of the jejunum of an experimentally infected puppy: 1 - granular dystrophy of enterocytes of crypts; 2 - subepithelial edema; 3 - ruination of enterocytes of crypts; hematoxylin and eosin

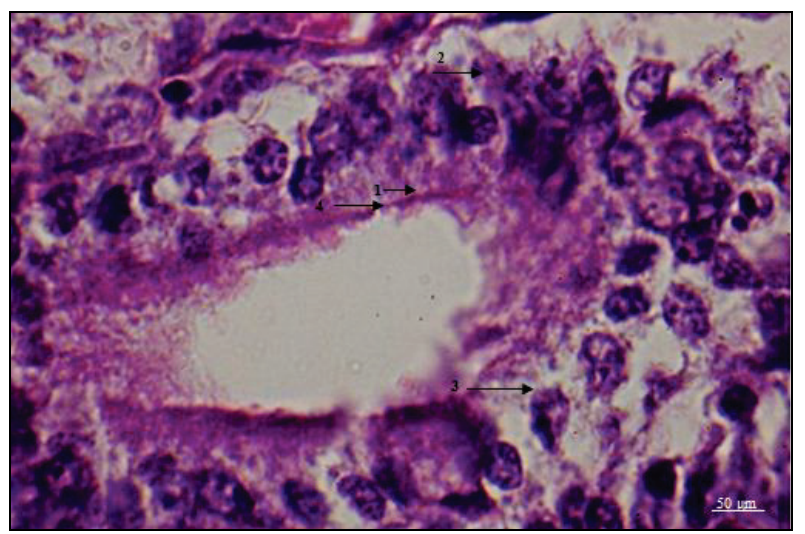

Fig. 15. Fragment of microscopic structure of the crypt of the duodenum of an experimentally infected puppy: 1 - granular dystrophy of enterocyte; 2 - partial lysis of cytoplasm of an enterocyte; 3 - enterocyte in the condition of hydropic dystrophy; 4 - dyscomplectation of adjacent enterocytes; hematoxylin and eosin 
In the jejunum and the ileum, we observed hyperplasia and hypertrophy of single and accumulated lymphoid nodes. However, despite the fact that the sizes of these nodes were increased compared to the similar formations in the control dogs, lymphocytes in them were located in a scattered way (Fig. 18).

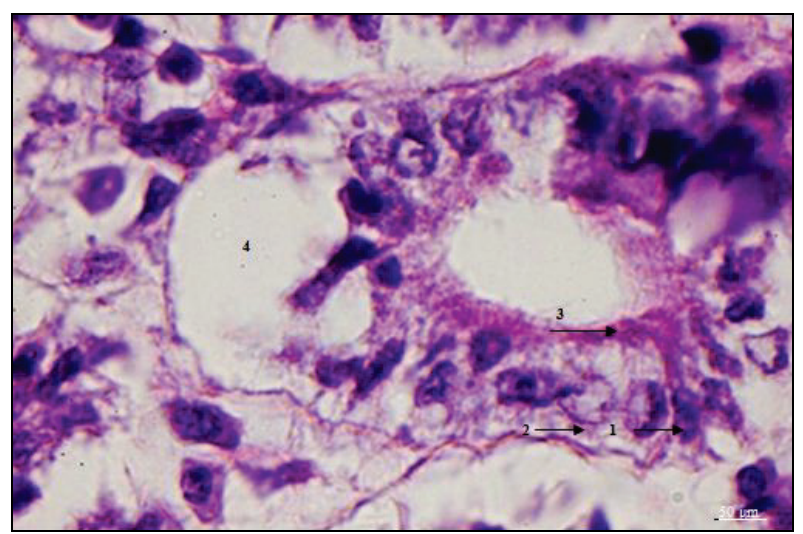

Fig. 16. Fragment of microscopic structure of the crypt of the ileum of an experimentally infected puppy: 1 - partial lysis of chromatin of nucleus of enterocyte in the condition of hydropic dystrophy; 2 - almost complete lysis of chromatin of nucleus of enterocyte in the condition of hydropic dystrophy; 3 - apical cytoplasm of enterocytes in the condition of hydropic dystrophy; 4 - subepithelial edema; hematoxylin and eosin

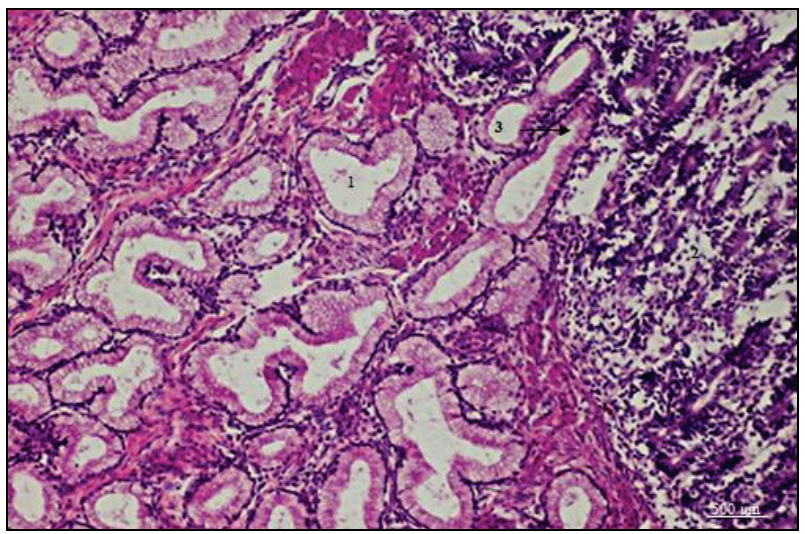

Fig. 17. Fragment of microscopic structure of the duodenum of an experimentally infected puppy: 1 - hypertrophied duodenal gland;

2 - mucous membrane; 3 - protrusion of the duodenal glands into the mucous membrane; hematoxylin and eosin

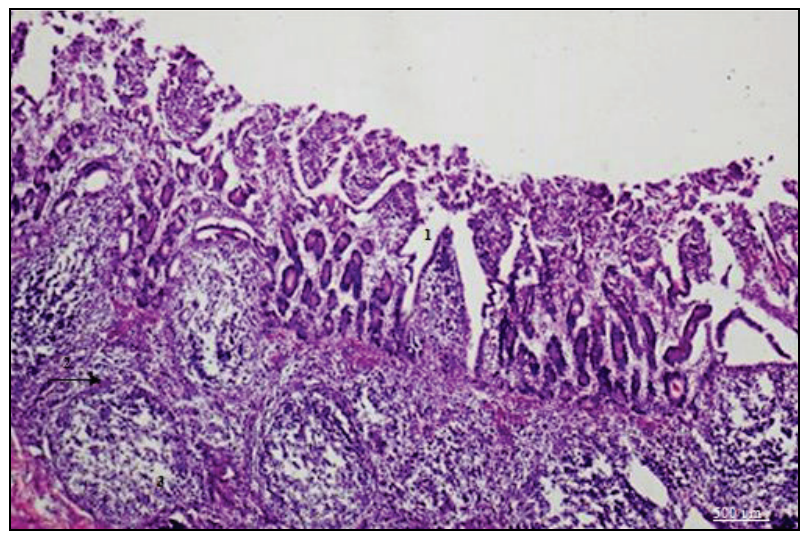

Fig. 18. Fragment of microscopic structure of the ileum of an experimentally infected puppy: 1 -mucous membrane;

2 - hypertrophied lymphoid node; 3 - scattered arrangement of lymphocytes in the hypertrophied lymphoid node; hematoxylin and eosin
In the internal layer of the muscularis, we found granular dystrophy of smooth cells and ruination of single dystrophically changed cells. In some places, usually near the external layer of this membrane, we detected cavities of different size and shape, which, in our opinion, were formed as a result of non-uniform edema of this internal layer. In the external layer of the muscularis, the microscopic changes were clearer than in the internal layer. Therefore, in addition to granular dystrophy of smooth myocytes, diffusive edema and their ruination were observed.

During staining of histological sections from different areas of the small intestine with alcian blue in $\mathrm{pH}$ of 1.0 and 2.5 , we observed no characteristic changes. Thus we came to the conclusion that during the canine coronavirus infection that we had experimentally recreated, mucoid edema of the basal membrane of the epithelium of the small intestine with neutral glycosaminoglycans occurred.

\section{Discussion}

Infectious intestinal diseases of dogs are often found in dog populations when kept in high density. One of the common pathogens is canine intestinal coronavirus, though currently not much is known about its pathogenesis and role, and the development of virus enteritis. Usually coronavirus enteritis has an accompanying course both with virus and bacterial infections, which very often leads to the death of the animal and does not allow identification of the characteristic peculiarities of the impact of coronavirus on the organism of dogs, as the Zoetis company informs us (Radzikhovsky, 2016). In our practice, in dogs, we often recorded combined infection by parvovirus and coronavirus enteritides (Lisova \& Radzikhovsky, 2018), where clinical signs (vomiting, diarrhea, depression, loss of appetite, dehydration) (Godsall et al., 2010; Caddy, 2018) and pathological-anatomical changes (in the liver, dense consistency of the pancreas and in the condition of dehydration, spleen with spotty hemorrhages, local infarctions in the kidneys, catarrhal-hemorrhagic inflammation of the mucous membrane of the gut, congestion of the vessels with blood, hemorrhagic inflammation of mesenterial lymph nodes) were similar to the natural course of coronavirus enteritides observed earlier (Buonavoglia et al., 2006; Zicola et al., 2012; Decaro et al., 2013).

Pathomorphological changes occurring during coronavirus infection in dogs are described in the available literature only in single literature sources and have a fragmented character (Zappulli et al., 2008; Perlman \& Netland, 2009; Mitchell et al., 2013). Therefore, the studies by domestic scientists describe the changes during the natural course of the disease (Lisova \& Dubinenko, 2017), while research involving experimental recreation of the coronavirus infection is described only in works by foreign authors (Tennant et al., 1991; Decaro et al., 2008; Decaro et al., 2012). At the same time, studies by Pratelli (2006) include data about non-uniform distribution of the infected intestinal villi during coronavirus enteritis (Pratelli, 2006). During experimental recreation of the coronavirus infection, in the infected dogs we observed necrosis of the apical parts of villi and their ruination in the small intestine. At the same time, similar changes were found extremely rarely, which partly coincides with the studies by other scientists (Perlman \& Netland, 2009; Fehr \& Perlman, 2015). At the same time, we observed granular and hydropic dystrophy of epitheliocytes of the intestinal crypts and ruination of part of erythrocytes. Furthermore, we found hyperplasia and hypertrophy of single accumulations of lymphoid nodes. Lymphocytes in them were scattered. In our opinion, the microscopic changes we observed in the small intestine can be related to the disorder of metabolic processes in the organism of puppies experimentally infected with coronavirus as a response to the action of the pathogen, which is indicated by our histochemical surveys (accumulation of enterocytes of the main and acidic proteins in cytoplasm, hypersecretion of mucus by goblet cells, decrease of SIA-positive substances in cytoplasm of enterocytes).

Moreover, according to the results of our studies, during staining of the histopreparations with hematoxylin and eosin, in the cytoplasm of single enterocytes of villi, basophilous inclusion bodies were found. Such cells had well preserved nuclei, and therefore could not be fragments of nuclei, which are formed over their ruination. As known, replication of canine coronavirus takes place in cytoplasm of the cells it had 
infected, and also reproduces in epithelial cells particularly of villi of the small intestine (Meese \& Blin, 1987; Licitra et al., 2014). Therefore, we can presume that these internal cytoplasmic basophilous inclusion bodies form as a result of infection of the enterocytes of villi by the disease pathogen and probably are its viral replication complex. However, we found such inclusion bodies only in single erythrocytes of villi, which does not correspond to general number of dystrophically changed and ruined cells. Moreover, in the available literature, we found no reports on formation of such internal plasmatic basophilous inclusion bodies in cells of dogs infected by coronavirus. Perhaps, formation of such inclusion bodies in the apical and middle parts of cytoplasm in single enterocytes of villi of the epithelial layer of the mucous membrane of the small intestine indicates re-structurizing of the organism of dogs, caused by the infectious process as a response to the pathogen of coronavirus.

Thus, the analysis of the literature data (Decaro et al., 2008; Decaro et al., 2012; Mitchell et al., 2013) and the results of our studies indicate a possibility of recreating the coronavirus infection in dogs by introducing biomaterial which contains the pathogen of coronavirus canis and prove that during experimental infection, the coronavirus infection was developing in all the animals.

At the same time, the coronavirus we isolated from a dead dog can be used for cultivating heterologous cell cultures and obtaining pathogenically cultural virus-containing material which can cause experimental recreation of coronavirus enteritis. Furthermore, histochemical changes in the small intestine of the infected dogs, where initial replication of the pathogen occurs, are characterized by peculiarities of tropism of coronavirus in experimentally infected animals. The knowledge of microscopic peculiarities of the pathogenic impact of coronavirus in the small intestine of dogs, which is presented in this paper, has made a significant contribution to understanding the pathogenesis of coronaviruses. The next goal will be determination and ultimate discovery of the nature of internal cytoplasmic basophilous inclusion bodies with use of methods of immunohistology and electron microscopy.

\section{Conclusion}

In dogs experimentally infected with cultivated coronavirus, its reproduction and ability to persist in the small intestine was observed due to significant accumulation of nucleic acids of the latter. At the same time, development of infectious process was related to the changes in histoarchitectonics of the small intestine and disorders of histochemical condition of cells, which leads to disorder in metabolic processes in the organism as a response to the action of pathogen.

The detected changes in the histostructure of the intestinal wall of the experimental dogs (ruination of villi, their necrosis, edema of the stroma, etc.) and cellular composition (granular and hydropic dystrophy of epiliocytes of villi, lysis of cytoplasm and deformation of nuclei of enterocytes), disorders in histochemical statics (accumulation of the main and acidic proteins in cytoplasm of enterocytes, hypersecretion of mucus by goblet cells, decrease in content of SIA-positive substances cytoplasm of enterocytes), formation of basophilous inclusion bodies in enterocytes of the experimentally infected dogs indicate restructuring of the organism due to infectious process caused by canine coronavirus.

In the experimentally infected dogs the microscopic changes in the small intestine were similar to those in spontaneously infected dogs. Under the effect of coronavirus, disorders in cellular contacts of enterocytes occur, leading to inhibition of protective functions of the intestine. At the same time, the pathological process in the experimentally infected animals developed faster and had a severer course. Also, hypersecretion of mucus by goblet cells is a protective mechanism against the development of the infectious process in animals subject to action of coronavirus.

The performed study is a part of the Scientific Study "Morphology, immunology of coronavirus infections (infectious bronchitis of chickens, coronavirus enteritis in dogs), their diagnosis and prevention", number of state registration 0118U003815".

\section{References}

Buonavoglia, C., Decaro, N., Martella, V., Elia, G., Campolo, M., Desario, C., Castagnaro, M., \& Tempesta, M. (2006). Canine coronavirus highly pathogenic for dogs. Emerging Infectious Diseases, 12(3), 492-496.

Caddy, S. L. (2018). New viruses associated with canine gastroenteritis. Veterinary, 232, 57-64

Decaro, N., Campolo, M., Lorusso, A., Desario, C., Mari, V., Colaianni, M., L. Elia, G., Martella, V., \& Buonavoglia, C. (2008). Experimental infection of dogs with a novel strain of canine coronavirus causing systemic disease and lymphopenia. Veterinary Microbiology, 128, 253-260.

Decaro, N., Cordonnier, N., Demeter, Z., Egberink, H., Elia, G., Grellet, A., Poder, S., Mari, V., Martella, V., Ntafis, V., Reitzenstein, M., Rottier, P. J., Rusvai, M., Shields, S., Xylouri, E., Xu, Z., \& Buonavoglia, C. (2013). European surveillance for pantropic canine coronavirus. Journal of Clinical Microbiology, 51(1), 83-88.

Decaro, N., Mari, V., Elia, G., Addie, D. D., Camero, M., Lucente, M. S., Martella, V., \& Buonavoglia, C. (2010). Recombinant canine coronaviruses in dogs, Europe. Emerging Infectious Diseases, 16(1), 41-47.

Decaro, N., Mari, V., Reitzenstein, M., Lucente, M. S., Cirone, F., Elia, G., Martella, V., King, V. L., Bello, A., Varello, K., Zhang, S., Caramelli, M., \& Buonavoglia, C. (2012). A pantropic canine coronavirus genetically related to the prototype isolate CB/05. Veterinary Microbiology, 159, 239-244.

Denison, M. R., Graham, R. L., Donaldson, E. F., Eckerle, L. D., \& Baric, R. S. (2011). Coronaviruses: An RNA proofreading machine regulates replication fidelity and diversity. RNA Biology, 8, 270-279.

Evermann, J. F., Abbott, J. R., \& Han, S. (2005). Canine coronavirus-associated puppy mortality without evidence of concurrent canine parvovirus infection. Journal of Veterinary Diagnostic Investigation, 17, 610-614.

Fehr, A. R., \& Perlman, S. (2015). Coronaviruses: An overview of their replication and pathogenesis. Methods in Molecular Biology, 1, 1282-1301.

Goddard, A., \& Leisewitz, A. L. (2010). Canine parvovirus. Veterinary Clinics of North America Small Animal Practice, 40(6), 1041-1053.

Godsall, S. A., Clegg, S. R., Stavisky, J. H., Radford, A. D., \& Pinchbeck, G. (2010). Epidemiology of canine parvovirus and coronavirus in dogs presented with severe diarthea to PDSA Pet Aid hospitals. Veterinary Record, 167, 196-201.

Goralsky, L. P., Khomich, V. T., \& Kononsky, O. I. (2015). Osnovy histolohichnoyi tekhniky i morfofunktsional'ni metody doslidzhen' u normi ta pry patolohiyi [Fundamentals of histological technique and morphofunctional methods of research in normal and pathology]. Zhytomyr (in Ukrainian).

He, B., Zhang, Y., Xu, L., Yang, W., Yang, F., Feng, Y., Xia, L., Zhou, J., Zhen, W., Feng, Y., Guo, H., Zhang, H., \& Tu, C. (2014). Identification of diverse alphacoronaviruses and genomic characterization of a novel severe acute respiratory syndrome-like coronavirus from bats in China. Journal of Virology, 88(12), 7070-7082.

Levy, G. A., Liu, M., Ding, J., Yuwaraj, S., Leibowitz, J., Marsden, P. A., Ning, Q., Kovalinka, A., \& Phillips, M. J. (2000). Molecular and functional analysis of the human prothrombinase gene (HFGL2) and its role in viral hepatitis. The American Journal of Pathology, 156, 1217-1225.

Licitra, B. N., Duhamel, G. E., \& Whittaker, G. R. (2014). Canine Enteric Coronaviruses: Emerging viral pathogens with distinct recombinant spike proteins. Viruses, 6(8), 3363-3376.

Lisova, V. V., \& Dubinenko, O. (2017). Histolohichni zminy v sobak za koronavirusnoyi infektsiyi [Histological changes in dogs with coronavirus infection]. Scientific Messenger of National University of Veterinary Medicine and Biotechnologies named after S. Z. Gzhytsky, 78(19), 154-157 (in Ukrainian).

Lisova, V. V., \& Radzikhovsky, M. L. (2018). Patomorfolohichna diahnostyka enterytiv virusnoyi etiolohiyi u sobak [Pathomorphological diagnostics of enteritis of viral etiology in dogs]. Scientific Messenger of National University of Veterinary Medicine and Biotechnologies named after S. Z. Gzhytsky, 83(20), 299-303 (in Ukrainian).

Meese, E., \& Blin, N. (1987). Simultaneous isolation of high molecular weight RNA and DNA from limited amounts of tissues and cells. Gene Analysis Techniques, 4, 45-49.

Mihindukulasuriya, K. A., Wu, G., Leger, S. J., Nordhausen, R. W., \& Wang, D. (2008). Identification of a novel coronavirus from a beluga whale by using a panviral microarray. Journal of Virology, 82(10), 5084-5088.

Mitchell, J. A., Brooks, H. W., Szladovits B., Erles K., Gibbons R., Shields S., \& Brownlie, J. (2013). Tropism and pathological findings associated with canine respiratory coronavirus (CRCoV). Veterinary Microbiology, 162, 582-594.

Mitchell, J. A., Cardwell, R. W., Renshaw, J. M, Dubovi, E. J., \& Brownlie, J. (2013). Detection of canine pneumovirus in dogs with canine infectious respiratory disease. Journal of Clinical Microbiology, 51(12), 4112-4119.

Netherton, C. L., \& Wileman, T. (2011). Virus factories, double membrane vesicles and viroplasm generated in animal cells. Current Opinion Virology, 1, 381-387.

Ntafis, V., Mari, V., Decaro, N., Papanastassopoulou, M., Papaioannou, N., Mpatziou, R., Buonavoglia, C., \& Xylouri, E. (2011). Isolation, tissue distribution and molecular characterization of two recombinant canine coronavirus strains. Veterinary Microbiology, 151, 238-244.

Perlman, S., \& Netland, J. (2009). Coronaviruses post-SARS: Update on replication and pathogenesis. Nature Reviews Microbiology, 7(6), 439-450. 
Poder, S. L. (2011). Rottier feline and canine coronaviruses: Common genetic and pathobiological features. Advances in Virology, 2011, 1-11.

Pratelli, A. (2006). Infection genetic evolution of canine coronavirus and recent advances in prophylaxis. Veterinary Research, 37(2), 191-200.

Radzikhovsky, M. L. (2016). Monitoryng enterytiv virusnoyi etiologiyi u sobak [Monitoring of enteritis of viral etiology in dogs]. Scientific Messenger of National University of Veterinary Medicine and Biotechnologies named after S. Z. Gzhytsky, 18, 138-142 (in Ukrainan).

Szczepanski, A., Owczarek, K., Milewska, A., Baster, Z., Rajfur, Z., Mitchell, J. A., \& Pyrc, K. (2018). Canine respiratory coronavirus employs caveolin-1-mediated pathway for internalization to HRT-18G cells. Veterinary Researh, 49(1), 1-15.

Tennant, B. J., Gaskell, R. M., Kelly, D. F., Carter, S. D., \& Gaskell, C. J. (1991) Canine coronavirus infection in the dog following oronasal inoculation. Journal of Research in Veterinary Science, 51(1), 11-19.
Vlasova, A. N., Halpin, R., Wang, S., Ghedin, E., Spiro, D. J., \& Saif, L. J. (2011) Molecular characterization of a new species in the genus Alphacoronavirus associated with mink epizootic catarrhal gastroenteritis. Journal of General Virology, 92(6), 1369-1379.

Woo, P. C., Huang, Y., Lau, S. K., \& Yuen, K. Y. (2010). Coronavirus genomics and bioinformatics analysis. Viruses, 2(8), 1804-1820.

Zappulli, V., Caliari, D., \& Cavicchioli, L. (2008). Systemic fatal type II coronavirus infection in a dog: Pathological findings and immunohistochemistry. Research in Veterinary Science, 84(2), 278-282.

Zicola, A., Jolly, S., Mathijs, E., Ziant, D., Decaro, N., Mari, V., \& Thiry, E. (2012). Fatal outbreaks in dogs associated with pantropic canine coronavirus in France and Belgium. Journal of Small Animal Practice, 53(5), 297-300. 